\title{
Diminishing Willingness to Pay per Quality-Adjusted Life Year: Valuing Acute Foodborne Illness
}

\author{
Kevin Haninger ${ }^{\mathrm{a}}$ and James K. Hammitt
}

August 2010

${ }^{a}$ AAAS Science \& Technology Policy Fellow, U.S. Environmental Protection Agency and Harvard University (Center for Risk Analysis) 1200 Pennsylvania Avenue, NW, Mail Code 5101T Washington, DC 20460

haninger.kevin@epa.gov

${ }^{\mathrm{b}}$ Harvard University (Center for Risk Analysis) and Toulouse School of Economics (LERNA-INRA)

21, allée de Brienne, 31000 Toulouse, France jkh@harvard.edu

\section{Acknowledgement}

This work was supported by the Economic Research Service of the United States Department of Agriculture and conducted while Kevin Haninger was at the Harvard Center for Risk Analysis. We thank Pierre Dubois, Joni Hersch, Nicolas Treich, W. Kip Viscusi, Milton Weinstein, and Ian Bateman for helpful comments. 


\begin{abstract}
We design and conduct a stated-preference survey to test whether willingness to pay (WTP) to reduce risk of acute illness is proportional to the corresponding gain in expected quality-adjusted life years (QALYs). For the short-term illnesses we consider, proportionality is required by economic theory if QALYs measure utility for health. Proportionality implies a constant WTP per incremental QALY and that WTP is proportional to changes in both health quality and duration of illness. WTP is elicited using double-bounded, dichotomous-choice questions in which respondents (randomly selected from the United States general adult population, $n=2,858$ ) decide whether to purchase a more expensive food to reduce the risk of foodborne illness. Health risks vary by baseline probability of illness, reduction in probability, duration and severity of illness, and conditional probability of mortality. The expected gain in QALYs is calculated using respondent-assessed decrements in health-related quality of life if ill combined with the duration of illness and reduction in probability specified in the survey. We reject the hypothesis that WTP is proportional to the change in expected QALYs and find diminishing marginal WTP for severity and duration of illness prevented. Our results suggest that individuals do not have a constant rate of WTP per QALY, which implies that costeffectiveness analysis using cost per expected QALY gained and measures of population health that assume a constant value per life year or QALY are not consistent with economic welfare theory.
\end{abstract}

Keywords: Quality-adjusted life year, willingness to pay, health risk, stated-preference, costeffectiveness analysis, foodborne illness

JEL: D61, I18, Q51 


\section{Introduction}

Willingness to pay (WTP) and quality-adjusted life years (QALYs) are alternative and commonly used methods of valuing health risk but there is little research on the empirical relationship between them. This relationship has important implications for the role of costeffectiveness analysis in evaluating policies that affect health and safety and for the use of QALY measures as an input to estimate WTP in benefit-cost analysis.

Cost-effectiveness analysis (CEA), which evaluates interventions by the cost per expected QALY gained, is consistent with economic-welfare theory and benefit-cost analysis (BCA) only if QALYs are a valid measure of utility and WTP per QALY gained is constant in the population (Johannesson, 1995; Garber and Phelps, 1997; Hammitt, 2002a). In the United States, federal agencies proposing regulations that primarily affect health and safety are required to supplement the required BCA with a CEA (U.S. OMB, 2003). If BCA and CEA are consistent, then presenting both analyses provides no additional information but simply offers alternative methods of framing the same information. If the two approaches are inconsistent, then it is not clear how decision makers are supposed to make use of the alternative perspectives.

Understanding the empirical relationship between WTP and QALY measures of health risk is also of interest because it may provide a basis for estimating WTP for use in BCA when no direct measures are available. There are few credible estimates of WTP to reduce morbidity endpoints and the number and diversity of such endpoints that are relevant to environmental, health, and safety regulation is so large that direct estimation of all the relevant values is infeasible. In standard analyses, the absence of good estimates often leads to the substitution of cost-of-illness values (e.g., for hospital admissions related to non-fatal effects of air pollution (as in EPA, 1999) or values of unrelated endpoints (e.g., an estimate of WTP to reduce risk of chronic bronchitis was used as a proxy for WTP to reduce risk of nonfatal bladder and lung cancers from arsenic in drinking water in EPA, 2001).

QALYs are calculated by weighting the period of time spent in each health state by the associated "health-related quality of life" (HRQL). Direct estimates of HRQL for many health states are available in the literature ${ }^{1}$ and such estimates can be relatively easily generated using generic health utility classification systems (e.g., Health Utilities Index, Feeny et al., 2002; EQ-

\footnotetext{
${ }^{1}$ For a convenient source, see the CEA registry at Tufts Medical Center, https://research.tuftsnemc.org/cear/default.aspx.
} 
5D, EuroQol Group, 1990). For example, Hubbell (2006) quantified the expected gain in QALYs due to regulations to control fine particulate air pollution by combining direct estimates of HRQL from the literature with estimated duration of effects. Miller et al. (2006) estimated QALY values of the health benefits of environmental, food-safety, and transportation-safety rules by estimating HRQL associated with relevant health states using several generic health utility classification systems.

If the relationship between expected gain in QALYs and WTP to reduce health risk were known, it would be straightforward to estimate WTP from the calculated gain in QALYs for each health effect. The most common approach is to assume that WTP per QALY is constant. Tolley et al. (1994) use this approach to place dollar values on alleviation of a wide range of health conditions. For example, they estimate WTP to alleviate a day of earache as the loss in HRQL (0.16) times the value of a statistical life-year $(\$ 120,000)$ divided by the number of days in a year, or $\$ 55$. The U.S. Food and Drug Administration and National Highway Traffic Safety Administration often use the same approach to value morbidity risks (Robinson, 2007). Similarly, scholarly attempts to quantify the value of historical gains in population health and longevity have assumed that economic value is proportional to QALYs (Cutler and Richardson, 1997) or at least to the components of QALYs: (discounted) life years (Nordhaus, 2003) and a measure of health (Murphy and Topel, 2006). Recognizing that WTP may not be proportional to expected QALYs gained, meta-analyses have been conducted to estimate a potentially nonlinear relationship between WTP and QALYs (e.g., Johnson et al., 1997; Van Houtven et al., 2003).

While it is clear that individual WTP per QALY varies with wealth, we consider the more fundamental question of whether an individual's WTP for a reduction in health risk is proportional to the expected gain in QALYs. We design and conduct a stated-preference survey to test whether WTP for a reduction in the risk of acute illness is proportional to the change in expected health and duration of illness, and hence proportional to the change in expected QALYs. The survey was completed by 3,902 randomly-selected adults in the United States. We reject the hypotheses that WTP is proportional to the loss of health-related quality of life (HRQL) and duration of illness and find that respondents exhibit diminishing marginal WTP for changes in these attributes. Our results suggest that WTP per QALY is not constant but depends on the expected gain in QALYs, and hence cost-effectiveness analysis is not consistent with economic-welfare theory and estimates of the value of health that assume a constant value per 
life year or QALY are invalid. We also find that the elasticity of WTP with respect to health (measured by gain in HRQL) differs from the elasticity of WTP with respect to duration of illness averted, which suggests that WTP per expected QALY gained differs between large but short-duration and small but long-duration gains in health. Hence, although WTP per QALY is not constant, it may be possible to estimate WTP as a function of the two dimensions (health quality and duration) separately.

In the following section we present the theoretical and empirical background for the study, review the literature on the value of reducing morbidity risk focusing on studies that are relevant to QALY measures of health, discuss the implications of economic theory for WTP per QALY, and develop an empirical model to test for proportionality. We describe the survey instrument and sample in Section 3. In Section 4, we report the results of regression models relating WTP to reduce risk of acute illness to the severity and duration of the illness, reduction in its probability, other risk attributes, and to demographic and preference characteristics of the respondents. We conclude in Section 5.

\section{Background}

In this section, we describe prior estimates of WTP per QALY, the implications of economic theory for the relationship between WTP and expected QALYs gained, and the empirical model we use to investigate this relationship.

\subsection{Prior Work}

Several studies have begun to explore the relationship between WTP and QALYs (O’Brien and Viramontes, 1994; Krabbe et al., 1997; Bala et al., 1998). Tolley et al. (1994) observe that directly elicited WTP is less than proportional to duration of improved health. It is unclear if this finding reflects insensitivity of the contingent valuation $(\mathrm{CV})$ method to the scope of the good being valued or genuine preferences.

Jones-Lee et al. (1995) elicit WTP to reduce the probabilities of traffic-related fatal and non-fatal injuries of varying severity and elicit probabilities of fatality for a standard gamble between fatality and complete recovery that respondents view as indifferent to each of the nonfatal injuries. They find that the ratio of WTP to prevent injury to WTP to prevent fatality is much larger than the standard gamble probability for the corresponding injury. They suggest this 
finding represents insensitivity of the WTP values to injury severity, although nonproportionality between WTP and HRQL could also contribute.

In a meta-analysis of five health-related CV studies, Johnson et al. (1997) examine WTP to avoid morbidity associated with 53 short-term health conditions. The authors assign an estimate of HRQL to each health condition using the Quality of Well Being Scale (QWB) (Kaplan et al., 1993) and estimate a generalized value function that places a dollar value on avoiding any short-term health condition that can be assigned a QWB score. The results show that WTP increases with both severity and duration of the illness avoided, although WTP is relatively insensitive to health quality for mild illnesses. Johnson et al. find evidence of increasing marginal WTP with severity and decreasing marginal WTP with duration of illness avoided. However, because rating-scale-based estimates of HRQL (such as the QWB) tend to exhibit an increasing convex relationship to standard-gamble and time-tradeoff estimates this result does not preclude a linear relationship between WTP and other measures of HRQL.

Van Houtven et al. (2003) expand the Johnson et al. (1997) meta-analysis. They also find that WTP increases more than proportionally with severity and less than proportionally with duration of illness averted. In addition, the authors find that avoiding losses of mobility and physical activity have statistically significant positive effects on WTP, while avoidance of other symptoms and limitations in social activity have smaller, insignificant effects on WTP.

Johnson et al. (2000) apply discrete-choice modeling to estimate WTP to reduce the risk of suffering acute episodes of respiratory and cardiovascular illness. They find that WTP increases less than proportionally with duration of illness averted. Gyrd-Hansen (2003) uses a similar technique to estimate WTP for improvements in chronic health in a random sample of the Danish population, using the EQ-5D (EuroQol Group, 1990) rather than the QWB to measure health. Both studies find evidence of variation in WTP for different attributes of health. In addition, Gyrd-Hansen's results suggest that WTP to improve health is not proportional to the EQ-5D score.

Hammitt (2002b) describes the set of utility functions for health, longevity, and wealth that are consistent with the assumptions that: (1) preferences for health and longevity, conditional on wealth, are consistent with QALYs; and (2) the HRQL for each health state is independent of wealth as (implicitly) assumed in the QALY literature. He finds that these conditions imply that marginal WTP per QALY is a decreasing function of future health and 
longevity. Hence, the assumption of constant WTP per QALY appears inconsistent with economic theory.

In summary, previous studies have found that marginal WTP to prevent an illness decreases with the duration of the illness avoided (Tolley et al., 1994; Johnson et al., 1997; Johnson et al., 2000; Van Houtven et al., 2003) but may increase with severity (Johnson et al., 1997; Van Houtven et al., 2003).

\subsection{Theory and Empirical Model}

WTP and QALYs are alternative methods of valuing reductions in health risk. WTP is defined as the compensating variation, i.e., the maximum amount of money an individual would exchange for the specified reduction in health risk. A closely related measure, willingness to accept (WTA), is defined as the equivalent variation, i.e., the minimum amount of money an individual would accept to forgo the reduction in health risk. For small changes in risk WTP and WTA should be nearly equal in magnitude although differences can arise for large changes in risk or when the risk change has no close substitutes (Hanemann, 1991).

QALYs are an alternative measure of individual utility for health that imposes additional structure on preferences. If an individual's preferences for health are consistent with QALYs they must satisfy several conditions including mutual utility independence of health and longevity, constant proportional tradeoff of longevity for health, and risk neutrality for longevity (Pliskin et al., 1980), or alternatively risk neutrality with respect to longevity for any health state and indifference to health quality for periods of zero duration (Bleichrodt et al., 1997). In addition, preferences for tradeoffs between health and longevity are invariably assumed to be independent of income (Hammitt, 2002a, 2002b).

Standard economic theory places few constraints on how WTP varies with the probability of suffering a health loss, except that WTP should increase with the severity of the potential health loss and WTP should be nearly proportional to the change in probability, for small changes (Hammitt, 2000; Corso et al., 2001).

Consider an individual facing a probability $r_{0}$ of suffering an acute illness. Her current HRQL is $h_{0}$; if she becomes ill, it will fall to $h_{1}<h_{0}$ for the duration of the illness and then recover to $h_{0}$. She is offered the opportunity to reduce the chance of falling ill to $r_{1}<r_{0}$. If her 
WTP to reduce the risk of illness is proportional to the gain in expected QALYs, then her WTP $v$ for this risk reduction is given by

$$
v=r h t m
$$

where $r=r_{0}-r_{1}$ is the reduction in probability of illness, $h=h_{0}-h_{1}$ is the decrement in HRQL while ill, $t$ is the duration of the illness, and $m$ is her rate of substitution between QALYs and income. (As noted above, Hammitt (2002b) finds that economic theory predicts marginal WTP per QALY is not constant but decreases with gains in health and longevity.) We test for proportionality of WTP to the expected change in QALYs and to each of the factors comprising it by embedding Equation (1) in a more general regression model that allows for nonproportionality of WTP to the risk reduction, decrement in HRQL, and duration of illness. We estimate the following generalization of the logarithm of Equation (1),

$$
\log (v)=\delta \log (r)+\alpha \log (h)+\beta \log (t)+\gamma \log \left(m_{0}\right)+X \theta+\varepsilon,
$$

where $X$ is a vector of characteristics of the respondent and health risk that may influence $m$, $m_{0}$ is the rate of substitution between QALYs and income when $X=0$, and $\varepsilon$ is a mean-zero error term. The scalars $\delta, \alpha, \beta, \gamma$, and the vector $\theta$ are coefficients.

Proportionality of WTP to the change in expected QALYs requires $\alpha=\beta=\delta=1$. If $\alpha$ is significantly different from one we reject the hypothesis of proportionality of WTP to HRQL. A value of $\alpha<1$ indicates diminishing marginal WTP to prevent an HRQL decrement and $\alpha>1$ indicates increasing marginal WTP for the averted health decrement. Similarly, if $\beta$ is significantly different from one we reject the assumption of a linear relationship between WTP and duration of illness. If $\beta<1 \mathrm{WTP}$ is less than proportional to duration of illness averted and $\beta>1$ implies that WTP increases more than proportionally with duration. The QALY formulation evaluates changes in health as the product $h t$ and hence requires $\alpha=\beta=1$.

If WTP is proportional to the change in probability of illness, $\delta=1$. For small changes in risk, near proportionality of WTP to probability of harm is implied by expected utility theory and most alternative theories of decision making under uncertainty (e.g., cumulative prospect theory; Kahneman and Tversky, 1992) except when there is a discontinuity in the probabilityweighting function for the relevant probabilities (Hammitt, 2000; Corso et al., 2001). For large changes in risk, WTP should be less than proportional to risk reduction because of the income or "high-payment" effect (Pratt and Zeckhauser, 1996) which reduces marginal WTP for successive 
risk increments. The magnitude of this effect depends on the income elasticity of marginal WTP per QALY and the total WTP for the change in health risk relative to income; e.g., if income elasticity is 1.0 and total WTP is 10 percent of income, then average WTP for the risk reduction is greater than 90 percent of marginal WTP for an infinitesimal risk reduction. Marginal WTP could also decrease for large risk reductions because of an analog of the "dead-anyway" effect (Pratt and Zeckhauser, 1996) if the marginal utility of income is smaller when sick than when well. For the short-term illnesses considered here, this effect should be negligible because the opportunity to shift consumption from the period of illness to periods of health implies the expected opportunity cost of spending to reduce health risk is not substantially affected by shortterm illness.

Despite the theoretical prediction, nearly all stated-preference studies of WTP for reductions in health risk that test for it find a less-than-proportional relationship between WTP and risk reduction (Hammitt and Graham, 1999). This result suggests inadequate sensitivity to scope, perhaps due to difficulties in communicating the magnitude of risk reduction to survey respondents or to respondents valuing the risk reduction formed by combining their prior estimates of the risk reduction with the value stated in the survey through a Bayesian updating process (Viscusi, 1985, 1989; Hammitt and Graham, 1999). Inadequate sensitivity to risk reduction would be reflected in an estimated value of $\delta<1$. Conversely, an estimated value of $\delta>1$ would imply excessive sensitivity to risk reduction that might occur if the risk is reduced to a non-zero level that respondents treat as equivalent to zero (as suggested by prospect theory; Kahneman and Tversky, 1979).

\section{Survey and Sample}

We design and conduct a stated-preference survey to elicit values for reductions in health risks that vary in the baseline probability of illness, reduction in probability, severity and duration of symptoms, and conditional probability of mortality. This section describes the survey instrument and sample.

\subsection{Survey Instrument}

The survey includes a dichotomous-choice experiment in which respondents decide whether to purchase a safer but more expensive food for preparation and consumption at home. 
The survey instrument is organized as follows. First, respondents are asked about their experience with foodborne illness and their perception of how common it is compared with other health and safety risks.

Second, respondents assess their current health using two alternative measures: a visual analog scale (VAS) and the Health Utilities Index Mark 3 (HUI). The VAS is a numbered line with endpoints of 0 and 100 labeled "equivalent to dead" and "perfect health," respectively. It is a standard measure of HRQL that has proven easy for respondents to answer. Although it does not explicitly assess a tradeoff of health for duration or risk of illness from which a cardinal measure of health quality can be derived, empirical evidence suggests a strong correlation between responses to VAS and alternative measures. The HUI is a generic, preference-based, multiattribute health-status classification system and index that is widely used as a measure of HRQL in clinical studies, population health surveys, and economic evaluation (Feeny et al., 2002). It classifies health according to the degree of function on eight dimensions: vision, hearing, speech, ambulation, dexterity, emotion, cognition, and pain. For each dimension, there are five or six levels that range from complete function to severe impairment. After the respondent evaluates how the illness would affect his functioning on each of these dimensions, the HRQL is calculated using a scoring function derived from prior calibration surveys in which respondents explicitly value HUI-described health states relative to a standard gamble between survival in perfect health and immediate death. In contrast to the VAS, the HUI is based on this cardinal standard-gamble measure, but assumes the functional relationship between impairment on each of the attributes and HRQL is common among individuals. We include alternative measures of HRQL in order to test for sensitivity of our results to the measure used.

Third, respondents complete a tutorial designed to help them practice making tradeoffs between the price and safety of food. The tutorial also familiarizes respondents with a visual aid that communicates the probability of illness (Corso et al., 2001). The visual aid contains red and white areas that represent 10,000 meals, where the fraction of the area that is colored red equals the probability of illness per meal.

Fourth, respondents are asked to consider buying food for a meal, to be prepared and eaten at home, that only they will eat. Respondents are asked whether they eat a type of food randomly selected from the set \{chicken, ground beef, packaged deli meat\}. If they do not eat the selected food, respondents are asked about another randomly-selected food from this set. After 
answering questions about how often they eat the food and what quantity they typically eat, respondents are presented with a description of the symptoms of foodborne illness associated with the food and are asked to imagine that they experience those symptoms. Respondents assess their health conditional on suffering the described illness using both the VAS and the HUI. By asking respondents to assess their health while ill immediately before the valuation questions, we hoped to focus their attention on the symptoms and severity of the illness.

Respondents are then told their baseline probability of illness (either 2 in 10,000 or 4 in 10,000 per meal) and informed that they could reduce their risk to 1 in 10,000 per meal by purchasing a safer but more expensive brand of food. The baseline probability of illness and reduction in probability are communicated using the visual aid described above. The risk reduction is described as produced by a stringent safety program established and monitored by the U.S. government that does not use chemicals or irradiation (some respondents might believe that chemicals or radiation would produce health risks). WTP to reduce the probability of illness is elicited using double-bounded, dichotomous-choice questions. Each respondent is asked if he would purchase the safer food if the extra cost per meal were a randomly selected amount from the set $\{\$ 0.04, \$ 0.10, \$ 0.20, \$ 0.50, \$ 1, \$ 2$, and $\$ 4\}$. The survey was administered in several waves and the initial bids were adjusted between waves to adequately capture the distribution of WTP. There is one follow-up question in which the bid is equal to twice the initial bid if the respondent is willing to pay the initial amount and equal to half the initial bid otherwise. A sample question is included in the Appendix.

After the valuation questions, respondents answer follow-up questions about their foodhandling practices, acceptance of the hypothetical scenario, and relevant personal characteristics. To investigate whether WTP to reduce health risk varies with financial risk aversion (Eeckhoudt and Hammitt, 2004), respondents are asked about their preferences with respect to income risks. They complete two dichotomous-choice questions that measure preferences for gambles on lifetime income based on questions from the Health and Retirement Study (Barsky et al., 1997). The first asks whether the respondent would prefer a job paying her current income for life or a 50-50 gamble between two jobs offering to double lifetime income or reduce it by one-third. A follow-up question is identical in form but alters the salary of the unfavorable job in the gamble to reduce income by one half or one fifth depending on whether the respondent accepted or 
rejected the initial gamble, respectively. The two questions can be used to classify respondents into four categories ordered by relative risk aversion.

Each respondent is asked to value two health-risk reductions that vary in baseline probability of illness, reduction in probability, severity and duration of symptoms, conditional probability of mortality, and type of food affected. Table 1 shows the risk attributes, which are based on the incidence, range of symptoms, and duration of foodborne illness in the United States. Risk attributes are randomly assigned using a full factorial design so that each of the 162 $\left(=2 \cdot 3^{4}\right)$ possible combinations is asked of some respondents. Respondents who live in a household with at least one child between the ages of 2 and 18 are asked about reducing one risk to their own health and one risk to the health of a randomly-selected child in their household (in random order). Other respondents are asked about reducing two risks to their own health. Respondents are not presented with the same food twice.

Because we suspected that respondents might exhibit a higher rate of WTP for risk reduction when considering a single meal rather than routine food expenditure, we constructed two versions of the survey. Respondents are randomly assigned to complete either the version described above, in which risks and costs are expressed per meal, or a version in which risks and costs are expressed per month. In the per-month version, both the risk and the bids are selected from the corresponding per-meal version and converted to monthly values using the respondent's self-reported frequency of consumption (assuming risk is independent across meals). If WTP is proportional to the expected gain in QALYs, estimated WTP will be identical using the per-meal and per-month framings.

\subsection{Sample}

The survey was fielded to 6,368 randomly-selected adults in the United States.

Respondents are members of a demographically representative panel maintained by Knowledge Networks. Households are recruited to the panel using random digital dialing and provided free internet access and hardware as a participation incentive. In total, 3,902 interviews were completed in several waves between August and October 2004 yielding a response rate of 61 percent. We report only results based on risks to the respondent's own health. For respondents who were asked about reducing risk to a child we include the response to the question about a risk to the respondent if it was the first valuation question but exclude it for the 588 respondents 
who are asked about reducing risk to a child's health before risk to their own health to protect against order effects. We also exclude 85 respondents who do not eat any of the three foods, 25 respondents who declined to answer the WTP questions, and 346 respondents who did not complete the HUI questions or who answered them inconsistently (by rating health in the event of sickness as better than current health). A total of 2,858 respondents and 4,851 risk reductions are included in the analysis.

\section{Results}

This section reports on respondent characteristics, estimated HRQL associated with current health and the illness presented in the survey, and how estimated WTP depends on attributes of the health risk, respondent characteristics, and other factors.

\subsection{Respondent Characteristics}

Table 2 lists the variables used for analysis with the means, standard deviations, and ranges for the sample of 2,858 respondents. Mean age is 46 years with a range of 18 to 96 years. Forty-eight percent of respondents are male. Seventy-four percent identify themselves as nonHispanic white, 12 percent as Hispanic, 10 percent as non-Hispanic black, and 3.8 percent as none of these categories. Fifty-two percent of respondents are married and the mean household size is 2.4 persons. Mean annual household income is about $\$ 48,100$. Twenty-six percent of respondents have a college degree. Thirty-nine percent report having contracted foodborne illness. On average, respondents estimate that 32 percent of the United States population contracts foodborne illness each year, a figure that is roughly compatible with an official estimate of 76 million cases per year (Mead et al., 1999) and suggests that respondents are wellinformed about this risk.

Respondents are significantly more likely to eat chicken and ground beef than packaged deli meat, which results in 40 percent of respondents answering their first question about chicken, 34 percent about ground beef, and 25 percent about packaged deli meat. On average, respondents report eating the food about which they are questioned (prepared at home) 5.7 times per month. There is some variation by food type: conditional on eating the specific food, respondents report eating chicken cooked at home 6.7 times per month, hamburger cooked at home 3.2 times per month, and packaged deli meats prepared at home 7.2 times per month. 
These rates appear consistent with national data. Including food eaten away from home, the 2003-2004 National Health and Nutrition Examination Survey (NHANES) reports total monthly consumption frequencies of chicken (9.9), hamburger (4.5), and three categories of packaged deli meats (turkey or chicken, 5.7, ham, 4.4, other cold cuts like bologna and salami, 4.4).

In follow-up questions related to food preparation, 55 percent of respondents indicate that they are responsible for preparing the food in their households most or all of the time, 62 percent report they consistently wash their hands while preparing the food, and 67 percent report taking one or more recommended steps to ensure that the food is fully cooked or otherwise safe to eat. In follow-up questions relating to acceptance of the hypothetical scenario, 47, 40, and 13 percent of respondents perceive their risk of foodborne illness to be similar to, smaller than, and larger than that presented in the survey, respectively. Eighty-four percent of respondents express at least some confidence that the safety system does not use chemicals or irradiation (as stated in the survey) and 4 and 6 percent believe the government and private sector are not at all effective in ensuring food safety, respectively.

As noted above, the two questions concerning gambles on lifetime income can be used to classify respondents into four categories ordered by relative risk aversion (toward financial risk). Fifty-six percent of respondents are in our most risk-averse class (Group I) and reject both the first and second gambles, 16 percent reject the first but accept the second gamble (Group II), 14 percent accept the first but reject the second gamble (Group III), and 15 percent accept both gambles (Group IV).

\subsection{Health-Related Quality of Life}

Table 3 reports the means and standard deviations of the HUI and VAS scores that respondents assign to current health and to the illness with which they are presented along with the symptom descriptions presented in the survey. The results show general agreement between the two measures of health. Mean HUI score for current health is 0.801 with a range of -0.195 to 1. Mean VAS score for current health is 0.756 with a range of 0.050 to 1 . Both HUI and VAS scores decrease with the severity of the illness presented. Mean HUI scores for "mild," "moderate," and "severe" symptom descriptions are $0.506,0.258$, and 0.116 , respectively. The corresponding mean VAS scores are $0.575,0.465$, and 0.420 , respectively. Consistent with other comparisons of rating-scale and standard-gamble estimates (Torrance, 1986; Torrance et al., 
1996), the VAS scores tend to cluster in the middle of the scale while the standard-gamble-based HUI scores are spread across a wider range. Comparisons between the VAS and HUI scores should recognize that possible scores for the VAS range between 0 and 1 while possible scores for the HUI range between -0.359 and 1 .

\subsection{Effects of Risk Attributes on WTP}

WTP is modeled as a function of the severity and duration of illness, reduction in its probability, other risk attributes, and respondent characteristics (Equation (2)). Because we elicited WTP using double-bounded dichotomous-choice questions, the dependent variable is interval-censored. Regression models are estimated using the maximum-likelihood method under the assumption that WTP is lognormally distributed (Alberini, 1995). Table 4 reports results based on pooling respondents who received either the version of the survey that expressed risks and costs per meal or the version that expressed risks and costs per month as well as separate results for each subsample.

To examine how WTP depends on health risk, we estimate a regression model that includes only variables for the reduction in the probability of illness, the decrement in HRQL associated with illness (as measured by the HUI), the duration of illness, and the conditional mortality risk (Models 1, 3, 5). We include a binary variable indicating whether risks and costs are expressed per meal or per month for the pooled sample (Model 1). Results of the pooled and subsample models are similar and we focus discussion on the pooled-sample results.

Model 1 confirms that WTP increases with the severity and duration of the illness to be prevented. We reject the hypotheses that WTP is insensitive to the HRQL decrement $(p<0.001)$ and to the duration of illness $(p=0.021)$. However, the estimated value of the coefficient $(\alpha)$ for the loss in HRQL is significantly smaller than one, which allows us to reject the hypothesis that WTP is proportional to the change in HRQL $(p<0.001)$. Similarly, the estimated coefficient $(\beta)$ for the duration of illness is significantly smaller than one, which allows us to reject the hypothesis that WTP is proportional to the duration of illness $(p<0.001)$. Taken together, the estimated coefficients for the loss in HRQL and duration of illness suggest diminishing marginal WTP for severity and duration of the illness to be prevented and hence that WTP to reduce the risk of illness varies less than proportionally to the QALYs potentially lost to illness. The estimated elasticities of WTP with respect to severity and duration are approximately 0.2 and 
0.1 , respectively. As described in Section 2.1, previous studies found that marginal WTP decreases with the duration but may increase with the severity of the illness to be prevented.

The estimated coefficient for risk reduction $(\delta)$ allows us to reject the hypothesis that WTP is insensitive to the change in probability $(p<0.001)$. Moreover, the estimated coefficient is significantly smaller than one, suggesting that WTP is less than proportional to the reduction in probability of illness $(p<0.001)$. These results are consistent with most previous studies that use stated-preference methods to estimate the value of reducing health risk (Hammitt and Graham, 1999). However, single-bounded models estimated using only the response to the initial bid suggest that estimated WTP is nearly proportional to the probability reduction (see Section 4.4 below). Hammitt and Haninger (2010) find nearly exact proportionality of WTP to change in probability of fatal disease or accident using the same visual aids for probability changes of 1 and 2 per 10,000 per year.

The estimated less-than-proportional relationships between WTP and both the severity and duration of illness (and hence to QALYs lost) might be explained by inadequate sensitivity of the stated-preference method to differences in these attributes rather than to diminishing marginal WTP. This explanation is not compelling, however, since we find that respondents are more sensitive to the change in probability of illness than to the severity and duration of illness (in every model, the estimated elasticity for risk reduction is substantially larger than the estimated elasticities for HRQL decrement and duration). While it is likely that well-known difficulties in understanding small probabilities (e.g., Kahneman and Tversky, 1973; Baron, 1997) contribute to the less-than-proportional relationship between estimated WTP and reduction in probability of illness (Hammitt and Graham, 1999; Corso et al., 2001), it is implausible that respondents are more cognizant of small differences in probability than of differences in duration (of 1,3 , and 7 days) and severity (which varies from mild illness that does not significantly interfere with daily activities to hospitalization).

The estimated coefficients of the conditional mortality risk variables are small and statistically insignificant in all six models reported in Table 4 . The lack of sensitivity to conditional mortality risk may reflect the very small reduction in absolute mortality risk, which ranges from 1 to 30 in 100 million. The largest point estimates of WTP to reduce mortality risk (Model 5) correspond to $\$ 0.10$ and $\$ 0.23$ per meal and imply values per statistical life of $\$ 2.7$ million and $\$ 66$ million for the 1 in 1,000 and 1 in 10,000 conditional mortality risks, 
respectively (estimated using predicted median WTP at sample mean). The smaller of these estimates is consistent with recommended values (e.g., \$4 million to \$9 million, Viscusi and Aldy, 2003; \$1.5 million to \$2.5 million, Mrozek and Taylor, 2002; \$1.5 million to \$4.8 million, Alberini et al., 2004).

Estimated WTP per unit risk reduction is estimated to be three times larger $(p<0.001)$ when the risk of illness, risk reduction, and bid amount are expressed per month rather than per meal. If WTP per expected QALY were constant the per-meal and per-month framings should yield identical estimates.

\subsection{Effects of Respondent Characteristics and Other Factors on WTP}

Models 2, 4 and 6 add respondent characteristics, other risk attributes, responses to follow-up questions, and interaction terms to the primary variables included in Models 1, 3, and 5. The addition of these variables has little effect on the estimated coefficients of the health risk attributes, which is expected given that the risk attributes were randomized independent of respondent characteristics. Estimates using the pooled sample and subsamples are similar (except as noted below) and we focus discussion on the pooled sample (Model 2).

Estimated WTP to reduce the risk of illness is significantly associated with respondent characteristics. Estimated WTP increases with age at a rate of 1.1 percent per year. Males are estimated to value risk reduction 25 percent less than females. Non-Hispanic blacks and Hispanics are estimated to value risk reduction about 2.4 and 2.0 times more, respectively, than non-Hispanic whites. Estimated WTP varies with marital status and household size but the results depend on whether risks and costs are expressed per meal or per month. When risks and costs are expressed per meal (Model 4), married respondents are estimated to value risk reduction 27 percent less than respondents who are not married with estimated WTP increasing at a rate of 8.8 percent per additional household member. When risks and costs are expressed per month (Model 6), the estimated coefficients are not significantly different from zero. The point estimates imply that married respondents value risk reduction 32 percent more than respondents who are not married $(p=0.055)$ with estimated WTP decreasing at a rate of 8.0 percent per additional household member $(p=0.198)$.

Respondents with a college degree are estimated to be willing to pay 23 percent less than respondents with less education, perhaps reflecting a better understanding of the small risk 
reduction. The estimated coefficient for household income is small, positive, and does not statistically significantly differ from zero $(p=0.270)$, potentially reflecting the low price of the risk reduction. Consistent with this hypothesis, the estimated coefficient for household income is larger and marginally significant $(p=0.054)$ when risks and costs are expressed per month (Model 6).

Estimated WTP to reduce the risk of illness is significantly associated with perceived risk and prior experience with foodborne illness. Respondents who perceive higher prevalence of foodborne illness in the United States are estimated to value the risk reduction more than respondents who perceive lower prevalence with estimated WTP increasing at a rate of 1.0 percent per percentage-point increase in perceived prevalence. Respondents who perceive their risk of foodborne illness to be higher or lower than that presented in the survey are estimated to value the risk reduction 47 percent more and 27 percent less, respectively, than respondents who perceive their risk to be similar to the stated magnitude. Respondents who report having contracted foodborne illness are estimated to value the risk reduction 17 percent less than other respondents although this effect is observed only when risks and costs are expressed per meal.

Estimated WTP to reduce the risk of illness is also significantly associated with acceptance of the hypothetical scenario. Respondents who are not confident that the safety system does not use chemicals or radiation (as stated in the survey) are estimated to value the risk reduction 60 percent less than respondents who express at least some confidence. Respondents who believe that the government and private sector are not at all effective in ensuring food safety are estimated to value the risk reduction 43 percent less and 69 percent more, respectively, than respondents who hold more favorable views. These results suggest that respondents are willing to pay more for the safety intervention when they believe that government regulation of the private sector is effective or necessary.

The type of food presenting the risk and the frequency of consumption are significantly associated with estimated WTP. Estimated WTP per unit risk reduction decreases with the monthly frequency of consumption at a rate of 1.5 percent per additional meal. Respondents are estimated to value reducing risk associated with chicken more than they value risks associated with ground beef and packaged deli meat but the estimated effects depend on question order. When comparing responses to the first risk reduction, respondents are estimated to value reducing a risk of illness associated with chicken 85 percent more than the value associated with 
ground beef and about twice as much as the value associated with packaged deli meat. We find no statistically significant differences between estimated WTP to reduce the risk of illness associated with ground beef and packaged deli meat. Question order has a marginally significant effect on the estimated coefficients for ground beef and packaged deli meat, but not on the estimated coefficient for chicken. Respondents are estimated to value reducing risk associated with ground beef 35 percent more if it is the second risk reduction as opposed to the first ( $p=$ 0.070 ) and packaged deli meat 36 percent more if it is the second risk reduction as opposed to the first $(p=0.091)$.

Estimated WTP also varies with protective behaviors related to food preparation. Respondents who have more responsibility for food preparation in their household are estimated to value the risk reduction less than others, with estimated WTP decreasing at a rate of 6.6 percent per point on a five-point scale. Respondents who consistently wash their hands when preparing the selected food are estimated to value the risk reduction 53 percent more than others. When risks and costs are expressed per meal, respondents who report taking one or more recommended steps to ensure that the food is fully cooked or otherwise safe to eat are estimated to value the risk reduction 35 percent more than respondents who do not engage in such protective behaviors. However, when risks and costs are expressed per month, respondents who report taking these steps are estimated to value the risk reduction 24 percent less than other respondents, although the estimated coefficient is not statistically significant ( $p=0.198)$.

While it is often claimed that individuals who are "more risk averse" will have higher WTP to avoid health risk, there is no general theoretical relationship between aversion to financial risk and WTP to reduce health risk (Eeckhoudt and Hammitt, 2004). Empirically, we find a non-monotonic relation. WTP is largest for the most risk-averse respondents (Group I) but increases as risk aversion decreases among the other three categories. Compared with Group I respondents, Group II respondents are estimated to value the health risk reduction 35 percent less $(p<0.001)$, Group III respondents value the health risk reduction 18 percent less $(p=0.059)$, and the least risk-averse respondents (Group IV) value the health risk reduction 12 percent less $(p=0.212)$. Results for the subsample for whom risk and WTP were expressed per month differ slightly as the least risk-averse respondents (Group IV) are estimated to value the health risk reduction less than the Group III respondents and 32 percent less $(p=0.055)$ than the most riskaverse respondents (Group I). 


\subsection{Sensitivity Analysis}

We examine the sensitivity of our results to several factors including question order, biases associated with double-bounded valuation questions, endogeneity of the estimated severity of illness, alternative measures of HRQL, and omitted respondent characteristics.

To test for effects of question order, we estimate Model 7 using only responses to the first risk reduction and Model 8 using only responses to the second risk reduction. The results are shown in Table 5. The estimated coefficients have the same signs and similar magnitudes in both models suggesting that question order has little effect on our results.

A concern when using double-bounded, dichotomous-choice valuation questions is that the initial bid may influence responses to the follow-up question yielding biased estimates of WTP (Alberini et al., 1997). To investigate the magnitude of any follow-up effect we estimate the six regression models in Table 4 using only the (single-bounded) response to the initial bid. We report the first of these models as Model 9 in Table 5. The single- and double-bounded estimates are similar with one important exception. The estimated coefficient for risk reduction is substantially larger in the single-bounded models, suggesting that estimated WTP may be proportional to the change in probability of illness. Using single-bounded estimates, we reject the hypothesis that WTP is insensitive to risk reduction but cannot reject or can only marginally reject the hypothesis that WTP is proportional to the risk reduction in three of the six regression models. For example, the estimated coefficient of the risk reduction in the single-bounded version of Model 4 is 0.821 (compared with 0.555 in the double-bounded model) and the $p$-value for rejecting the hypothesis of proportionality is 0.168 . Using the single-bounded estimates, we continue to reject the hypothesis that WTP is proportional to the probability reduction in singlebounded estimates of Model $1(p<0.001)$, Model $2(p<0.001)$, and Model $5(p<0.001)$.

The loss in HRQL is defined by the difference between a respondent's estimates of HRQL in current health and if suffering from the symptoms described in the survey instrument. If respondents who perceive the symptoms to be worse than other respondents perceive them to be report smaller HRQL and larger WTP to reduce the risk of illness, the estimated coefficient on loss in HRQL may be biased downward, causing us to erroneously reject the hypothesis that WTP is proportional to illness severity. To test for this bias, we estimate Model 10, which is identical to Model 1 (Table 4) except the respondent's loss in HRQL is calculated as the difference between her HUI score for current health and the (effectively exogenous) sample 
mean HUI score for the symptom description (for the subsample of respondents who evaluated those symptoms). The estimated coefficient for the loss in HRQL in Model 10 (0.344) is larger than the estimated coefficient in Model 1 (0.197), which suggests some downward bias in Model 1 due to endogeneity of the HRQL loss. Nevertheless, we continue to reject the hypothesis that WTP is proportional to change in HRQL $(p<0.001)$.

Estimates of HRQL using alternative instruments exhibit systematic variation (Torrance, 1986). To test the dependence of our conclusions on the measure used, we estimate Model 11, which is identical to Model 1 (Table 4) but substitutes a variable for HRQL loss derived using the VAS rather than the HUI. The estimated coefficient for the loss in VAS score in Model 11 (0.140) is somewhat smaller than the estimated coefficient for the loss in HUI score in Model 1 (0.197), although in both cases we reject the hypothesis that WTP is proportional to change in HRQL $(p<0.001)$.

The estimated coefficients for the risk attributes may be biased by failure to control for unobserved individual characteristics. We test for this bias by taking advantage of the fact that most respondents value two health-risk reductions, which allows us to estimate a regression model describing the difference in WTP for the two reductions in health risk as a function of the differences in probability, severity, and duration of the illnesses. Using Equation (2), the difference in the logarithm of WTP to reduce each of two health risks is given by

$$
\log \left(v_{1}-v_{2}\right)=\delta \log \left(r_{1}-r_{2}\right)+\alpha \log \left(h_{1}-h_{2}\right)+\beta \log \left(t_{1}-t_{2}\right)+\left(X_{1}-X_{2}\right) \theta+\varepsilon_{1}-\varepsilon_{2}
$$

where $r_{1}-r_{2}$ is the difference in the reduction in probability of illness between the first and second health risks, $h_{1}-h_{2}$ is the difference in the decrement in HRQL while ill, $t_{1}-t_{2}$ is the difference in the duration of the illness, and $X_{1}-X_{2}$ are other covariates that differ between health risks. The bounds on the interval-censored dependent variable can be calculated from the bounds on the WTP for each risk reduction. Any individual-specific error term and fixed respondent characteristics in Equation (2) cancel when deriving Equation (3). Estimates of Equation (3) are shown as Model 12 (Table 5). The estimated coefficients are similar to the estimated coefficients in Model 1 (Table 4), providing evidence that unobserved individual characteristics do not affect our main conclusions. However, the estimated coefficients for the conditional mortality risks are substantially larger and, in the case of the larger risk, marginally significant $(p=0.091)$. 


\subsection{Value per Statistical Case of Foodborne Illness}

Table 6 reports estimates of the value per statistical case of foodborne illness stratified by the severity of symptoms, duration of illness, and conditional mortality risk. The estimates are calculated using Model 1 (Table 4) to predict median WTP of the sample-mean respondent for each risk reduction and dividing by the mean reduction in probability of illness (i.e., $\log$ (WTP) is predicted by summing the products of each coefficient with the value of the corresponding variable at its sample mean, then exponentiating to estimate median WTP). Assuming no conditional mortality risk, the estimated values range from $\$ 4,500$ for mild symptoms that last one day to $\$ 6,500$ for severe symptoms that last seven days. The small proportional difference between these values reflects the less-than-proportional relationships between estimated WTP and both duration and severity of illness.

The average value per QALY is reported in the last column of Table 6. Expected QALYs lost conditional on illness and fatality were estimated for each respondent using the respondentspecific decrement in HRQL while ill and age-sex-specific life expectancy assuming that upon recovery HRQL returns to the respondent's current level and maintains that level for the remainder of her life. The average WTP per QALY ranges from about $\$ 150,000$ to $\$ 5.6$ million. These values are substantially larger than the $\$ 50,000$ to $\$ 100,000$ values often noted in the CEA literature and closer to values imputed by allocating conventional estimates of VSL over life expectancy (typically less than $\$ 500,000$; Hirth et al., 2000). Because WTP varies less than proportionately with the decrement in HRQL and duration of illness, the average WTP per QALY is smaller for the cases with more severe symptoms and longer durations. In addition, because estimated WTP is not sensitive to conditional mortality risk the average WTP per QALY is smaller for cases with greater mortality risk.

\section{Conclusion}

In a survey of the general adult United States population we find that WTP to reduce the risk of illness increases with, but is less than proportional to, severity and duration of acute illness. We find that respondents exhibit diminishing marginal WTP for severity and duration of illness avoided. WTP is estimated to be more sensitive to severity of the illness (measured by loss in HRQL) than to duration, with elasticities of about 0.2 for severity ( 0.3 corrected for endogeneity) and 0.1 for duration. Previous studies have also found that marginal WTP 
decreases with duration of illness avoided (e.g., Tolley et al., 1994; Johnson et al., 1997; Van Houtven et al., 2003) but some studies have found that marginal WTP increases with severity (Johnson et al., 1997; Van Houtven et al., 2003).

Our results suggest that individuals do not have a constant WTP per expected QALY for avoidance of short-term morbidity. Rather, marginal WTP per expected QALY is a decreasing function, consistent with theory (Hammitt, 2002b). This implies that estimates of WTP to avoid non-fatal health risk based on multiplying the corresponding loss in QALYs by a constant monetary value per QALY are not valid. Moreover, our results suggest that while WTP to reduce morbidity risk is an increasing function of severity and duration of the illness to be prevented, WTP is more sensitive to severity than to duration, and so WTP cannot be represented as a univariate function of expected QALYs gained. Further research should examine whether these results may be generalized to illnesses of longer duration.

This study provides empirical support for the claim that individual WTP per QALY depends on the quantity of expected QALYs. Hence economic analyses that rely on a single WTP-per-QALY value to estimate the value of an endpoint for which direct WTP estimates are unavailable or to estimate population gains in health are inconsistent with economic welfare theory. Moreover, cost-effectiveness analysis using QALYs is inconsistent with benefit-cost analysis. The results of these analyses can imply different conclusions about appropriate policy choice and should be defended on non-welfarist or other grounds (e.g., Adler, 2006; Culyer, 1989, 1990). 


\section{References}

Adler, M., "QALYs and Policy Evaluation: A New Perspective," Yale Journal of Health Policy, Law and Ethics 6: 1-92, 2006.

Alberini, A., "Efficiency vs. Bias of Willingness-to-Pay Estimates: Bivariate and Interval-Data Models," Journal of Environmental Economics and Management 29: 169-180, 1995.

Alberini, A., M. Cropper, A. Krupnick, and N. Simon, "Does the Value of a Statistical Life Vary with Age and Health Status? Evidence from the US and Canada," Journal of Environmental Economics and Management 48: 769-792, 2004.

Bala, M.V., L.L. Wood, G.A. Zarkin, E.C. Norton, A. Gafni, and B. O’Brien, "Valuing Outcomes in Health Care: A Comparison of Willingness to Pay and Quality-Adjusted Life Years," Journal of Clinical Epidemiology 51: 667-676, 1998.

Baron, J., "Biases in the Quantitative Measurement of Values for Public Decisions," Psychological Bulletin 122: 72-88, 1997.

Barsky, R.B., F.T. Juster, M.S. Kimball, and M.D. Shapiro, "Preference Parameters and Behavioral Heterogeneity: An Experimental Approach in the Health and Retirement Study," Quarterly Journal of Economics 112: 537-580, 1997.

Bleichrodt, H., P. Wakker, and M. Johannesson, "Characterizing QALYs by Risk Neutrality," Journal of Risk and Uncertainty 15: 107-114, 1997.

Corso, P.S., J.K. Hammitt, and J.D. Graham, "Valuing Mortality-Risk Reduction: Using Visual Aids to Improve the Validity of Contingent Valuation," Journal of Risk and Uncertainty 23(2): 165-184, 2001.

Culyer, A.J., "Commodities, Characteristics of Commodities, Characteristics of People, Utilities, and the Quality of Life," in S. Baldwin, C. Godfrey, and C. Propper, eds., Quality of Life: Perspectives and Policies, Routledge, London, 1990.

Culyer, A.J., "The Normative Economics of Health Care Finance and Provision," Oxford Review of Economic Policy 5: 34-58, 1989.

Cutler, D.M., and E. Richardson, "Measuring the Health of the U.S. Population," Brookings Papers on Economic Activity: Microeconomics 97: 217-271, 1997.

Eeckhoudt, L.R., and J.K. Hammitt, "Does Risk Aversion Increase the Value of Mortality Risk?" Journal of Environmental Economics and Management 47: 13-29, 2004.

EuroQol Group, "EuroQoL - A New Facility for the Measurement of Health-Related Quality of Life," Health Policy 16(3): 199-208, 1990.

Feeny, D., W. Furlong, G.W. Torrance, C.H. Goldsmith, Z. Zhu, S. DePauw, M. Denton, and M. Boyle, "Multiattribute and Single-Attribute Utility Functions for the Health Utilities Index Mark 3 System,” Medical Care 40: 113-128, 2002.

Garber, A.M., and C.E. Phelps, "Economic Foundations of Cost-Effectiveness Analysis," Journal of Health Economics 16: 1-31, 1997.

Gyrd-Hansen, D., "Willingness to Pay for a QALY," Health Economics 12: 1049-1060, 2003. 
Hammitt, J.K. "Evaluating Contingent Valuation of Environmental Health Risks: The Proportionality Test," Association of Environmental and Resource Economists Newsletter 20(1): 14-19, May 2000. Reprinted in Stated Preference: What Do We Know? Where Do We Go? (Proceedings), Report number EE-0436, U.S. Environmental Protection Agency, October 2000.

Hammitt, J.K., “QALYs versus WTP,” Risk Analysis 22(5): 985-1001, 2002a.

Hammitt, J.K., "How Much is a QALY Worth? Admissible Utility Functions for Health and Wealth," Harvard Center for Risk Analysis, 2002b.

Hammitt, J.K., and J.D. Graham, "Willingness to Pay for Health Protection: Inadequate Sensitivity to Probability?" Journal of Risk and Uncertainty 18(1): 33-62, 1999.

Hammitt, J.K., and K. Haninger, "Valuing Fatal Risks to Children and Adults: Effects of Disease, Latency, and Risk Aversion," Journal of Risk and Uncertainty 40: 57-83, 2010.

Hanemann, M.W., "Willingness to Pay and Willingness to Accept: How Much Can They Differ?" American Economic Review 81: 635-647, 1991.

Hanemann, W.M., J. Loomis, and B. Kanninen, "Statistical Efficiency of Double-Bounded Dichotomous Choice Contingent Valuation," American Journal of Agricultural Economics 73: 1255-1261, 1991.

Hirth, R.A., M.E. Chernew, E. Miller, A.M. Fendrick, and W.G. Weissert, "Willingness to Pay for a Quality-Adjusted Life Year: In Search of a Standard," Medical Decision Making 20: 332-342, 2000.

Hubbell, B.L. "Implementing QALYs in the Analysis of Air Pollution Regulations," Environmental and Resource Economics 34: 365-384, 2006.

Johannesson, M., "The Relationship between Cost-Effectiveness Analysis and Cost-Benefit Analysis," Social Science and Medicine 41: 483-489, 1995.

Johnson F.R., E.E. Fries, and H.S. Banzhaf, "Valuing morbidity: an integration of the willingness-to-pay and health-status index literatures," Journal of Health Economics 16: 641-665, 1997.

Johnson, F.R., M.R. Banzhaf, and W.H. Desvousges, "Willingness to Pay for Improved Respiratory and Cardiovascular Health: A Multiple-Format, Stated-Preference Approach," Health Economics 9: 295-317, 2000.

Jones-Lee, M.W., G. Loomes, and P.R. Philips, "Valuing the Prevention of Non-Fatal Road Injuries: Contingent Valuation vs. Standard Gambles," Oxford Economic Papers 47: 676695, 1995.

Kahneman, D., and A. Tversky, "On the Psychology of Prediction," Psychology Review 80: 237$251,1973$.

Kahneman, D., and A. Tversky, "Prospect Theory: An Analysis of Decision under Risk," Econometrica 47: 263-291, 1979.

Kaplan, R.M., J.P. Anderson, and T.G. Ganiats, "The Quality of Well-Being Scale: Rationale for a Single Quality of Life Index," in Walker, S.R., and R.M. Rosser (eds.), Quality of Life Assessment: Key Issues in the 1990s, Kluwer, Dordrecht, 1993. 
Krabbe, P.F.M., M. Essink-Bot, and G.J. Bonsel, "The Comparability and Reliability of Five Health-State Valuation Methods. Social Science and Medicine 45: 1641-1652, 1997.

Mead, P.S., L. Slutsker, V. Dietz, L.F. McCaig, J.S. Bresee, C. Shapiro, P.M. Griffin, and R.V. Tauxe, "Food-Related Illness and Death in the United States," Emerging Infectious Diseases 5: 840-842, 1999.

Miller, W., L.A. Robinson, and R.S. Lawrence, eds., Valuing Health for Regulatory CostEffectiveness Analysis, Institute of Medicine, National Academies Press, Washington, DC, 2006.

Mrozek, J.R., and L.O. Taylor, "What Determines the Value of Life? A Meta-Analysis," Journal of Policy Analysis and Management 21: 253-270, 2002.

Murphy, K.M., and R.H. Topel, “The Value of Health and Longevity,” Journal of Political Economy 114: 871-904, 2006.

Nordhaus, W.D., "The Health of Nations: The Contribution of Improved Health to Living Standards," in Measuring the Gains from Medical Research: An Economic Approach (K.H. Murphy and R.H. Topel, eds.), University of Chicago Press, Chicago, 2003.

O’Brien, B., and J.L. Viramontes, "Willingness to Pay: A Valid and Reliable Measure of Health State Preference?” Medical Decision Making 14: 289-297, 1994.

Pliskin, J.S., D.S. Shepard, and M.C. Weinstein, "Utility Functions for Life Years and Health Status," Operations Research 28: 206-224, 1980.

Pratt, J.W., and R.J. Zeckhauser, "Willingness to Pay and the Distribution of Risk and Wealth," Journal of Political Economy 104: 747-763, 1996.

Robinson, L.A., "How U.S. Government Agencies Value Mortality Risk Reductions," Review of Environmental Economics and Policy 1: 283-299, 2007.

Tolley, G., D. Kenkel, and R. Fabian (eds.), Valuing Health for Policy: An Economic Approach, University of Chicago Press, Chicago, 1994.

Torrance, G.W, D.H. Feeny, W.J. Furlong, R.D. Barr, Y. Zhang, Q. Wang, “Multiattribute Utility Function for a Comprehensive Health Status Classification System: Health Utilities Index Mark 2," Medical Care 34: 702-722, 1996.

Torrance, G.W., "Measurements of Health State Utilities for Economic Appraisal," Journal of Health Economics 5: 1-30, 1986.

Tversky, A., and D. Kahneman, "Advances in Prospect Theory: Cumulative Representation of Uncertainty," Journal of Risk and Uncertainty 5: 297-323, 1992.

U.S. Environmental Protection Agency (EPA), "National Primary Drinking Water Regulations: Arsenic and Clarifications to Compliance and New Source Contaminants Modeling," Federal Register 66 (14): 6975-6066, January 22, 2001.

U.S. Environmental Protection Agency (EPA), The Benefits and Costs of the Clean Air Act, 1990 to 2010, EPA 410-R-99-001, Washington, D.C., 1999.

U.S. Office of Management and Budget (OMB), "Regulatory Analysis," Circular A-4, Office of Information and Regulatory Affairs, Washington, D.C., September 17, 2003. 
Van Houtven, G., M. Rousu, J.-C. Yang, C. Pringle, W. Wagstaff, and J. DePlatchett, Valuation of Morbidity Losses: Meta-Analysis of Willingness-to-Pay and Health Status Measures, Research Triangle Institute, 2003.

Viscusi, W.K, "Prospective Reference Theory: Toward an Explanation of the Paradoxes," Journal of Risk and Uncertainty 2: 235-263, 1989.

Viscusi, W.K., "A Bayesian Perspective on Biases in Risk Perception," Economic Letters 17: 5962,1985

Viscusi, W.K., and J.E. Aldy, "The Value of a Statistical Life: A Critical Review of Market Estimates throughout the World," Journal of Risk and Uncertainty 27: 5-76, 2003. 
Table 1. Risk Attributes (Full-Factorial Design)

\begin{tabular}{clcll}
\hline $\begin{array}{c}\text { Risk } \\
\text { Reduction }\end{array}$ & $\begin{array}{c}\text { Severity of } \\
\text { Symptoms }\end{array}$ & $\begin{array}{c}\text { Duration } \\
\text { of Illness }\end{array}$ & $\begin{array}{c}\text { Conditional } \\
\text { Mortality }\end{array}$ & Type of Food \\
\hline 1 in 10,000 & Mild & 1 day & None & Chicken \\
3 in 10,000 & Moderate & 3 days & 1 in 10,000 & Ground Beef \\
& Severe & 7 days & 1 in 1,000 & Packaged Deli Meat \\
\hline
\end{tabular}


Table 2 Variables and Descriptive Statistics

\begin{tabular}{|c|c|c|c|}
\hline Variable & Mean & Std. Dev. & Range \\
\hline Log of Risk Reduction & -8.308 & 0.943 & {$[-9.210,-4.703]$} \\
\hline Log of Loss in HUI Score & -0.906 & 0.794 & {$[-4.500,0.252]$} \\
\hline Log of Duration of Illness & 0.968 & 0.799 & {$[0,1.946]$} \\
\hline \multicolumn{4}{|l|}{ Conditional Mortality Risk } \\
\hline 1 in 1,000 & 0.313 & 0.464 & {$[0,1]$} \\
\hline 1 in 10,000 & 0.338 & 0.473 & {$[0,1]$} \\
\hline None & 0.348 & 0.477 & {$[0,1]$} \\
\hline Age & 45.802 & 16.680 & {$[18,96]$} \\
\hline Male & 0.475 & 0.499 & {$[0,1]$} \\
\hline \multicolumn{4}{|l|}{ Race and Ethnicity } \\
\hline White, Non-Hispanic & 0.741 & 0.438 & {$[0,1]$} \\
\hline Hispanic & 0.115 & 0.320 & {$[0,1]$} \\
\hline Black, Non-Hispanic & 0.105 & 0.306 & {$[0,1]$} \\
\hline Other, Non-Hispanic & 0.038 & 0.192 & {$[0,1]$} \\
\hline Married & 0.519 & 0.500 & {$[0,1]$} \\
\hline Household Size & 2.423 & 1.270 & {$[1,9]$} \\
\hline Log of Household Income & 10.457 & 0.928 & {$[7.247,12.206]$} \\
\hline College Degree & 0.262 & 0.440 & {$[0,1]$} \\
\hline Perceived Prevalence of Foodborne Illness & 31.850 & 22.862 & {$[0,100]$} \\
\hline \multicolumn{4}{|l|}{ Perception of Own Risk Versus Stated Risk } \\
\hline Perceive Own Risk to be Higher & 0.125 & 0.331 & {$[0,1]$} \\
\hline Perceive Own Risk to be the Same & 0.472 & 0.499 & {$[0,1]$} \\
\hline Perceive Own Risk to be Lower & 0.402 & 0.490 & {$[0,1]$} \\
\hline Prior Foodborne Illness & 0.388 & 0.487 & {$[0,1]$} \\
\hline \multicolumn{4}{|l|}{ Confidence in Safety System } \\
\hline Not Confident & 0.346 & 0.476 & {$[0,1]$} \\
\hline Somewhat Confident & 0.493 & 0.500 & {$[0,1]$} \\
\hline Very Confident & 0.161 & 0.368 & {$[0,1]$} \\
\hline Low Trust in Government & 0.039 & 0.193 & {$[0,1]$} \\
\hline Low Trust in Private Sector & 0.062 & 0.241 & {$[0,1]$} \\
\hline \multicolumn{4}{|l|}{ Type of Food } \\
\hline Chicken & 0.403 & 0.491 & {$[0,1]$} \\
\hline Ground Beef & 0.345 & 0.475 & {$[0,1]$} \\
\hline Packaged Deli Meat & 0.252 & 0.434 & {$[0,1]$} \\
\hline Monthly Frequency of Consumption & 5.654 & 6.344 & {$[1,30]$} \\
\hline Degree of Responsibility for Preparing Food & 2.402 & 1.477 & {$[0,4]$} \\
\hline Wash Hands & 0.615 & 0.487 & {$[0,1]$} \\
\hline Safe Food Practices & 0.674 & 0.469 & {$[0,1]$} \\
\hline Financial Risk Aversion & & & {$[0,1]$} \\
\hline I. Reject First and Second Gambles & 0.559 & 0.497 & {$[0,1]$} \\
\hline II. Reject First and Accept Second Gambles & 0.158 & 0.364 & {$[0,1]$} \\
\hline III. Accept First and Reject Second Gambles & 0.138 & 0.345 & {$[0,1]$} \\
\hline IV. Accept First and Second Gambles & 0.146 & 0.353 & {$[0,1]$} \\
\hline Second Risk & 0.411 & 0.492 & {$[0,1]$} \\
\hline Second Risk $\times$ Chicken & 0.153 & 0.360 & {$[0,1]$} \\
\hline Second Risk $\times$ Ground Beef & 0.152 & 0.359 & {$[0,1]$} \\
\hline Second Risk $\times$ Packaged Deli Meat & 0.106 & 0.307 & {$[0,1]$} \\
\hline Monthly Version & 0.283 & 0.451 & {$[0,1]$} \\
\hline Monthly Version $\times$ Married & 0.144 & 0.351 & {$[0,1]$} \\
\hline Monthly Version $\times$ Household Size & 0.669 & 1.234 & {$[0,7]$} \\
\hline Monthly Version $\times$ Safe Food Practices & 0.191 & 0.393 & {$[0,1]$} \\
\hline Monthly Version $\times$ Prior Foodborne Illness & 0.110 & 0.313 & {$[0,1]$} \\
\hline
\end{tabular}

Note: Statistics are based on the first risk presented to the sample of 2,858 respondents, with the exception of variables relating to question order. A total of 1,993 respondents were also asked about a second risk. 
Table 3. HUI and VAS Scores Assigned to Current Health and to Symptoms of Illness

\begin{tabular}{|c|c|c|c|c|}
\hline \multirow[b]{2}{*}{ Health State } & \multicolumn{2}{|c|}{ HUI Score } & \multicolumn{2}{|c|}{ VAS Score } \\
\hline & Mean & Std. Dev. & Mean & Std. Dev. \\
\hline Current Health & 0.801 & 0.205 & 0.756 & 0.165 \\
\hline $\begin{array}{l}\text { Mild Symptoms } \\
\text { You will have an upset stomach and will feel tired, but } \\
\text { these symptoms will not prevent you from going to work } \\
\text { or from doing most of your regular activities. }\end{array}$ & 0.506 & 0.269 & 0.575 & 0.207 \\
\hline $\begin{array}{l}\text { Moderate Symptoms } \\
\text { You will have an upset stomach, fever, and will need to } \\
\text { lie down most of the time. You will be tired and will not } \\
\text { feel like eating or drinking much. Occasionally, you will } \\
\text { have painful cramps in your stomach. In addition, you } \\
\text { will have some diarrhea and will need to stay close to a } \\
\text { bathroom. While you are sick, you will not be able to go } \\
\text { to work or do most of your regular activities. }\end{array}$ & 0.258 & 0.305 & 0.465 & 0.227 \\
\hline $\begin{array}{l}\text { Severe Symptoms } \\
\text { You will have to be admitted to a hospital. You will have } \\
\text { painful cramps in your stomach, fever, and will need to } \\
\text { spend most of your time lying in bed. You will need to } \\
\text { vomit and will have severe diarrhea that will leave you } \\
\text { seriously dehydrated. Because you will be unable to eat } \\
\text { or drink much, you will need to have intravenous tubes } \\
\text { put in your arm to provide nourishment. }\end{array}$ & 0.116 & 0.310 & 0.420 & 0.249 \\
\hline
\end{tabular}

Note: Possible scores range between 0 and 1 for the VAS and -0.359 and 1 for the HUI. 
Table 4. Regression Results

\begin{tabular}{|c|c|c|c|c|c|c|}
\hline \multirow[b]{2}{*}{ Variable } & \multicolumn{2}{|c|}{ Pooled } & \multicolumn{2}{|c|}{ Per Meal } & \multicolumn{2}{|c|}{ Per Month } \\
\hline & Model 1 & Model 2 & Model 3 & Model 4 & Model 5 & Model 6 \\
\hline Intercept & $\begin{array}{l}5.156^{* * *} \\
(0.419)\end{array}$ & $\begin{array}{l}4.894 * * * \\
(0.669)\end{array}$ & $\begin{array}{l}4.950^{* * *} \\
(0.705)\end{array}$ & $\begin{array}{l}4.891^{* * *} \\
(0.904)\end{array}$ & $\begin{array}{l}6.373^{* * *} \\
(0.450)\end{array}$ & $\begin{array}{l}5.015^{* * *} \\
(1.216)\end{array}$ \\
\hline Log of Risk Reduction $(\delta)$ & $\begin{array}{l}0.516^{* * * *} \\
(0.047)\end{array}$ & $\begin{array}{l}0.583 * * * \\
(0.049)\end{array}$ & $\begin{array}{l}0.490 * * * \\
(0.080)\end{array}$ & $\begin{array}{l}0.559 * * * \\
(0.077)\end{array}$ & $\begin{array}{l}0.535^{* * * *} \\
(0.057)\end{array}$ & $\begin{array}{l}0.549 * * * \\
(0.097)\end{array}$ \\
\hline Log of Loss in HUI Score $(\alpha)$ & $\begin{array}{l}0.197 * * * \\
(0.046)\end{array}$ & $\begin{array}{l}0.196^{* * *} \\
(0.045)\end{array}$ & $\begin{array}{l}0.171^{* * *} \\
(0.055)\end{array}$ & $\begin{array}{l}0.186^{* * *} \\
(0.053)\end{array}$ & $\begin{array}{l}0.259 * * * \\
(0.083)\end{array}$ & $\begin{array}{l}0.220^{* * *} \\
(0.083)\end{array}$ \\
\hline Log of Duration of Illness $(\beta)$ & $\begin{array}{l}0.105^{* *} \\
(0.046)\end{array}$ & $\begin{array}{l}0.105^{* *} \\
(0.044)\end{array}$ & $\begin{array}{c}0.106^{*} \\
(0.055)\end{array}$ & $\begin{array}{l}0.111^{* *} \\
(0.052)\end{array}$ & $\begin{array}{c}0.108 \\
(0.082)\end{array}$ & $\begin{array}{c}0.107 \\
(0.080)\end{array}$ \\
\hline Conditional Mortality Risk of 1 in 1,000 & $\begin{array}{l}-0.003 \\
(0.090)\end{array}$ & $\begin{array}{c}0.025 \\
(0.086)\end{array}$ & $\begin{array}{l}-0.047 \\
(0.108)\end{array}$ & $\begin{array}{c}0.006 \\
(0.103)\end{array}$ & $\begin{array}{c}0.086 \\
(0.162)\end{array}$ & $\begin{array}{c}0.075 \\
(0.159)\end{array}$ \\
\hline Conditional Mortality Risk of 1 in 10,000 & $\begin{array}{c}0.045 \\
(0.089)\end{array}$ & $\begin{array}{c}0.043 \\
(0.085)\end{array}$ & $\begin{array}{l}-0.020 \\
(0.106)\end{array}$ & $\begin{array}{c}0.022 \\
(0.101)\end{array}$ & $\begin{array}{c}0.199 \\
(0.161)\end{array}$ & $\begin{array}{c}0.142 \\
(0.158)\end{array}$ \\
\hline Age & & $\begin{array}{l}0.011^{* * *} \\
(0.002)\end{array}$ & & $\begin{array}{l}0.012 * * * \\
(0.003)\end{array}$ & & $\begin{array}{c}0.007 * \\
(0.004)\end{array}$ \\
\hline Male & & $\begin{array}{l}-0.289^{* * *} \\
(0.076)\end{array}$ & & $\begin{array}{l}-0.339 * * * \\
(0.091)\end{array}$ & & $\begin{array}{l}-0.196 \\
(0.141)\end{array}$ \\
\hline Black, Non-Hispanic & & $\begin{array}{l}0.888^{* * * *} \\
(0.129)\end{array}$ & & $\begin{array}{l}0.810^{* * * *} \\
(0.156)\end{array}$ & & $\begin{array}{l}1.038^{* * *} \\
(0.230)\end{array}$ \\
\hline Hispanic & & $\begin{array}{l}0.708^{* * * *} \\
(0.121)\end{array}$ & & $\begin{array}{l}0.662^{* * * *} \\
(0.141)\end{array}$ & & $\begin{array}{l}0.820 \text { *** } \\
(0.235)\end{array}$ \\
\hline Other Race, Non-Hispanic & & $\begin{array}{l}-0.063 \\
(0.187)\end{array}$ & & $\begin{array}{l}-0.246 \\
(0.216)\end{array}$ & & $\begin{array}{c}0.364 \\
(0.374)\end{array}$ \\
\hline Married & & $\begin{array}{l}-0.317 * * * \\
(0.093)\end{array}$ & & $\begin{array}{l}-0.314 * * * \\
(0.096)\end{array}$ & & $\begin{array}{c}0.280^{*} \\
(0.146)\end{array}$ \\
\hline Household Size & & $\begin{array}{l}0.076^{* *} \\
(0.038)\end{array}$ & & $\begin{array}{l}0.085^{* *} \\
(0.040)\end{array}$ & & $\begin{array}{l}-0.084 \\
(0.065)\end{array}$ \\
\hline Log of Household Income & & $\begin{array}{c}0.047 \\
(0.043)\end{array}$ & & $\begin{array}{c}0.018 \\
(0.051)\end{array}$ & & $\begin{array}{r}0.151^{*} \\
(0.078)\end{array}$ \\
\hline College Degree & & $\begin{array}{l}-0.259 * * * \\
(0.083)\end{array}$ & & $\begin{array}{l}-0.201^{* *} \\
(0.098)\end{array}$ & & $\begin{array}{l}-0.442 * * * \\
(0.160)\end{array}$ \\
\hline Perceived Prevalence & & $\begin{array}{l}0.010^{* * *} \\
(0.002)\end{array}$ & & $\begin{array}{l}0.014^{* * *} \\
(0.002)\end{array}$ & & $\begin{array}{c}0.002 \\
(0.003)\end{array}$ \\
\hline Perceive Own Risk to be Higher & & $\begin{array}{l}0.385^{* * *} \\
(0.115)\end{array}$ & & $\begin{array}{l}0.329^{* *} \\
(0.129)\end{array}$ & & $\begin{array}{l}0.687 * * * \\
(0.260)\end{array}$ \\
\hline Perceive Own Risk to be Lower & & $\begin{array}{l}-0.320 * * * \\
(0.077)\end{array}$ & & $\begin{array}{l}-0.305^{* * *} \\
(0.093)\end{array}$ & & $\begin{array}{l}-0.323^{* *} \\
(0.140)\end{array}$ \\
\hline Prior Foodborne Illness & & $\begin{array}{l}-0.158^{*} \\
(0.088)\end{array}$ & & $\begin{array}{l}-0.182 * * \\
(0.089)\end{array}$ & & $\begin{array}{c}0.125 \\
(0.136)\end{array}$ \\
\hline Not Confident in Safety System & & $\begin{array}{l}-0.928 * * * \\
(0.106)\end{array}$ & & $\begin{array}{l}-1.030 * * * \\
(0.125)\end{array}$ & & $\begin{array}{l}-0.646 * * * \\
(0.202)\end{array}$ \\
\hline Somewhat Confident in Safety System & & $\begin{array}{l}-0.053 \\
(0.080)\end{array}$ & & $\begin{array}{l}-0.016 \\
(0.094)\end{array}$ & & $\begin{array}{l}-0.117 \\
(0.148)\end{array}$ \\
\hline Low Trust in Government & & $\begin{array}{l}-0.557 * * * \\
(0.197)\end{array}$ & & $\begin{array}{l}-0.557 * * \\
(0.227)\end{array}$ & & $\begin{array}{l}-0.498 \\
(0.385)\end{array}$ \\
\hline
\end{tabular}


Table 4. Regression Results (continued)

\begin{tabular}{|c|c|c|c|c|c|c|}
\hline \multirow[b]{2}{*}{ Variable } & \multicolumn{2}{|c|}{ Pooled } & \multicolumn{2}{|c|}{ Per Meal } & \multicolumn{2}{|c|}{ Per Month } \\
\hline & Model 1 & Model 2 & Model 3 & Model 4 & Model 5 & Model 6 \\
\hline Low Trust in Private Sector & & $\begin{array}{l}0.524 * * * \\
(0.166)\end{array}$ & & $\begin{array}{l}0.643^{* * *} \\
(0.202)\end{array}$ & & $\begin{array}{c}0.183 \\
(0.290)\end{array}$ \\
\hline Ground Beef & & $\begin{array}{l}-0.453 * * * \\
(0.109)\end{array}$ & & $\begin{array}{l}-0.573 * * * \\
(0.129)\end{array}$ & & $\begin{array}{l}-0.142 * \\
(0.203)\end{array}$ \\
\hline Packaged Deli Meat & & $\begin{array}{l}-0.494 * * * \\
(0.140)\end{array}$ & & $\begin{array}{l}-0.451 * * * \\
(0.164)\end{array}$ & & $\begin{array}{l}-0.557 * * * \\
(0.268)\end{array}$ \\
\hline Monthly Frequency of Consumption & & $\begin{array}{l}-0.015 * * \\
(0.006)\end{array}$ & & $\begin{array}{l}-0.019 * * * \\
(0.007)\end{array}$ & & $\begin{array}{c}0.002 \\
(0.018)\end{array}$ \\
\hline Responsibility for Preparing Meals & & $\begin{array}{l}-0.068 * * \\
(0.028)\end{array}$ & & $\begin{array}{l}-0.080^{* *} \\
(0.033)\end{array}$ & & $\begin{array}{l}-0.047 \\
(0.053)\end{array}$ \\
\hline Wash Hands & & $\begin{array}{l}0.426^{* * *} \\
(0.073)\end{array}$ & & $\begin{array}{l}0.346^{* * *} \\
(0.086)\end{array}$ & & $\begin{array}{l}0.571 \text { *** } \\
(0.135)\end{array}$ \\
\hline Safe Food Practices & & $\begin{array}{l}0.240^{* *} \\
(0.119)\end{array}$ & & $\begin{array}{l}0.300^{* *} \\
(0.128)\end{array}$ & & $\begin{array}{l}-0.277 \\
(0.215)\end{array}$ \\
\hline Financial Risk Aversion Group II & & $\begin{array}{l}-0.430 * * * \\
(0.099)\end{array}$ & & $\begin{array}{l}-0.434 * * * \\
(0.118)\end{array}$ & & $\begin{array}{l}-0.410^{* *} \\
(0.184)\end{array}$ \\
\hline Financial Risk Aversion Group III & & $\begin{array}{l}-0.201^{*} \\
(0.106)\end{array}$ & & $\begin{array}{l}-0.202^{*} \\
(0.121)\end{array}$ & & $\begin{array}{l}-0.207 \\
(0.225)\end{array}$ \\
\hline Financial Risk Aversion Group IV & & $\begin{array}{l}-0.132 \\
(0.106)\end{array}$ & & $\begin{array}{l}-0.044 \\
(0.124)\end{array}$ & & $\begin{array}{l}-0.382 * \\
(0.199)\end{array}$ \\
\hline Second Risk & & $\begin{array}{c}0.042 \\
(0.116)\end{array}$ & & $\begin{array}{l}-0.041 \\
(0.139)\end{array}$ & & $\begin{array}{c}0.238 \\
(0.212)\end{array}$ \\
\hline Second Risk $\times$ Ground Beef & & $\begin{array}{c}0.303^{*} \\
(0.167)\end{array}$ & & $\begin{array}{l}0.528^{* * * *} \\
(0.199)\end{array}$ & & $\begin{array}{l}-0.279 \\
(0.309)\end{array}$ \\
\hline Second Risk $\times$ Packaged Deli Meat & & $\begin{array}{c}0.307^{*} \\
(0.182)\end{array}$ & & $\begin{array}{l}0.429 * * \\
(0.215)\end{array}$ & & $\begin{array}{l}-0.096 \\
(0.337)\end{array}$ \\
\hline Monthly Version & $\begin{array}{l}1.124^{* * * *} \\
(0.100)\end{array}$ & $\begin{array}{l}1.270^{* * *} \\
(0.233)\end{array}$ & & & & \\
\hline Monthly Version $\times$ Married & & $\begin{array}{l}0.607^{* * * *} \\
(0.161)\end{array}$ & & & & \\
\hline Monthly Version $\times$ Household Size & & $\begin{array}{l}-0.150^{* *} \\
(0.069)\end{array}$ & & & & \\
\hline Monthly Version $\times$ Safe Food Practices & & $\begin{array}{l}-0.354^{* *} \\
(0.167)\end{array}$ & & & & \\
\hline Monthly Version $\times$ Prior Foodborne Illness & & $\begin{array}{l}0.215 \\
(0.161)\end{array}$ & & & & \\
\hline Sigma & $\begin{array}{l}2.110 \\
(0.045)\end{array}$ & $\begin{array}{l}1.981 \\
(0.042)\end{array}$ & $\begin{array}{l}2.135 \\
(0.054)\end{array}$ & $\begin{array}{l}1.981 \\
(0.050)\end{array}$ & $\begin{array}{c}2.034 \\
(0.080)\end{array}$ & $\begin{array}{l}1.932 \\
(0.076)\end{array}$ \\
\hline Sample Size & 4,851 & 4,851 & 3,481 & 3,481 & 1,370 & 1,370 \\
\hline Log Likelihood & $-5,481.8$ & $-5,224.3$ & $-3,925.5$ & -3712.3 & $-1,554.5$ & $-1,492.8$ \\
\hline
\end{tabular}

Note: Standard errors are in parentheses. ${ }^{* *}, * *$, and $*$ denote statistical significance at 1,5 , and 10 percent, respectively, based on likelihood-ratio tests. 
Table 5. Sensitivity Analysis

\begin{tabular}{lllllll}
\hline Variable & Model 7 & Model 8 & Model 9 & Model 10 & Model 11 & Model 12 \\
\hline Intercept & $5.088^{* * *}$ & $5.318^{* * *}$ & $6.644^{* * *}$ & $5.211^{* * *}$ & $5.152^{* * *}$ & $-0.191^{* * *}$ \\
& $(0.544)$ & $(0.654)$ & $(0.688)$ & $(0.423)$ & $(0.424)$ & $(0.057)$ \\
Log of Risk Reduction $(\delta)$ & $0.516^{* * *}$ & $0.524^{* * *}$ & $0.620^{* * *}$ & $0.517^{* * *}$ & $0.518^{* * *}$ & $0.534^{* * *}$ \\
& $(0.061)$ & $(0.073)$ & $(0.076)$ & $(0.047)$ & $(0.047)$ & $(0.053)$ \\
Log of Loss in HUI Score $(\alpha)$ & $0.150^{* *}$ & $0.263^{* * *}$ & $0.284^{* * *}$ & & & $0.398^{* * *}$ \\
& $(0.062)$ & $(0.069)$ & $(0.074)$ & & & $(0.070)$ \\
Log of Mean Loss in HUI Score by Severity & & & & $0.344^{* * *}$ & & \\
$(\alpha)$ & & & & & & \\
& & & & $(0.104)$ & & \\
Log of Loss in VAS Score $(\alpha)$ & & & & & $0.140^{* *}$ & \\
& & & & & $(0.058)$ & \\
Log of Duration of Illness $(\beta)$ & 0.085 & $0.131^{*}$ & $0.137^{*}$ & $0.117 * *$ & $0.107^{* *}$ & $0.142^{* * *}$ \\
& $(0.060)$ & $(0.069)$ & $(0.073)$ & $(0.046)$ & $(0.046)$ & $(0.050)$ \\
Conditional Mortality Risk of 1 in 1,000 & -0.057 & 0.067 & -0.145 & 0.018 & 0.007 & $0.168^{*}$ \\
& $(0.119)$ & $(0.137)$ & $(0.144)$ & $(0.090)$ & $(0.090)$ & $(0.099)$ \\
Conditional Mortality Risk of 1 in 10,000 & -0.042 & 0.167 & -0.017 & 0.068 & 0.057 & 0.123 \\
& $(0.116)$ & $(0.137)$ & $(0.142)$ & $(0.089)$ & $(0.089)$ & $(0.098)$ \\
Monthly Version & $1.181^{* * *}$ & $1.023^{* * *}$ & $1.161^{* * *}$ & $1.118^{* * *}$ & $1.119^{* * *}$ & \\
Sigma & $(0.131)$ & $(0.154)$ & $(0.160)$ & $(0.100)$ & $(0.100)$ & \\
Sample Size & 2.142 & 2.047 & 2.989 & 2.113 & 2.115 & 1.302 \\
Log Likelihood & $(0.059)$ & $(0.068)$ & $(0.154)$ & $(0.045)$ & $(0.049)$ & $(0.052)$ \\
\hline
\end{tabular}

Note: Standard errors are in parentheses. ${ }^{* *},{ }^{* *}$, and ${ }^{*}$ denote statistical significance at 1,5 , and 10 percent, respectively, based on likelihood-ratio tests. 
Table 6. Estimated Value per Statistical Case of Foodborne Illness and WTP per QALY (US\$)

\begin{tabular}{lllll}
\hline $\begin{array}{l}\text { Severity of } \\
\text { Symptoms }\end{array}$ & $\begin{array}{c}\text { Duration of } \\
\text { Illness }\end{array}$ & $\begin{array}{c}\text { Conditional } \\
\text { Mortality }\end{array}$ & Value per Case & WTP per QALY \\
\hline Mild & 1 day & None & $\$ 4,500$ & $\$ 5,587,000$ \\
Moderate & 1 day & None & $\$ 5,100$ & $\$ 3,425,000$ \\
Severe & 1 day & None & $\$ 5,300$ & $\$ 2,841,000$ \\
\hline Mild & 3 days & None & $\$ 5,100$ & $\$ 2,090,000$ \\
Moderate & 3 days & None & $\$ 5,700$ & $\$ 1,281,000$ \\
Severe & 3 days & None & $\$ 6,000$ & $\$ 1,063,000$ \\
\hline Mild & 7 days & None & $\$ 5,500$ & $\$ 979,000$ \\
Moderate & 7 days & None & $\$ 6,200$ & $\$ 600,000$ \\
Severe & 7 days & None & $\$ 6,500$ & $\$ 498,000$ \\
\hline Mild & 1 day & 1 in 10,000 & $\$ 4,700$ & $\$ 1,283,000$ \\
Moderate & 1 day & 1 in 10,000 & $\$ 5,300$ & $\$ 1,221,000$ \\
Severe & 1 day & 1 in 10,000 & $\$ 5,600$ & $\$ 1,173,000$ \\
\hline Mild & 3 days & 1 in 10,000 & $\$ 5,300$ & $\$ 1,000,000$ \\
Moderate & 3 days & 1 in 10,000 & $\$ 6,000$ & $\$ 815,000$ \\
Severe & 3 days & 1 in 10,000 & $\$ 6,200$ & $\$ 736,000$ \\
\hline Mild & 7 days & 1 in 10,000 & $\$ 5,800$ & $\$ 679,000$ \\
Moderate & 7 days & 1 in 10,000 & $\$ 6,500$ & $\$ 492,000$ \\
Severe & 7 days & 1 in 10,000 & $\$ 6,800$ & $\$ 427,000$ \\
\hline Mild & 1 day & 1 in 1,000 & $\$ 4,500$ & $\$ 152,000$ \\
Moderate & 1 day & 1 in 1,000 & $\$ 5,100$ & $\$ 168,000$ \\
Severe & 1 day & 1 in 1,000 & $\$ 5,300$ & $\$ 173,000$ \\
\hline Mild & 3 days & 1 in 1,000 & $\$ 5,000$ & $\$ 162,000$ \\
Moderate & 3 days & 1 in 1,000 & $\$ 5,700$ & $\$ 172,000$ \\
Severe & 3 days & 1 in 1,000 & $\$ 6,000$ & $\$ 173,000$ \\
\hline Mild & 7 days & 1 in 1,000 & $\$ 5,500$ & $\$ 160,000$ \\
Moderate & 7 days & 1 in 1,000 & $\$ 6,200$ & $\$ 159,000$ \\
Severe & 7 days & 1 in 1,000 & $\$ 6,500$ & $\$ 156,000$ \\
\hline
\end{tabular}

Note: Estimates are based on predicted median WTP for sample-mean respondent using Model 1. 


\section{Appendix}

The table below summarizes the differences between the Superior Safety System chicken and the standard chicken. Please consider which type of chicken you would buy for a meal that only you would eat. Remember that the extra money you spend for a meal with Superior Safety System chicken is money that you could no longer spend on other things you might want or need.

\begin{tabular}{ccc}
\hline Type of Chicken & $\begin{array}{c}\text { Your Chance of } \\
\text { Illness per Meal }\end{array}$ & Cost per Meal \\
\hline $\begin{array}{c}\text { Standard } \\
\text { Superior Safety System }\end{array}$ & 4 in 10,000 & $\begin{array}{c}\text { standard cost } \\
\text { standard chicken }\end{array}$ \\
\hline
\end{tabular}

Whether you eat the Superior Safety System chicken or the standard chicken, if you get sick:

- You will have an upset stomach, fever, and will need to lie down most of the time. You will be tired and will not feel like eating or drinking much. Occasionally, you will have painful cramps in your stomach. In addition, you will have some diarrhea and will need to stay close to a bathroom. While you are sick, you will not be able to go to work or do most of your regular activities.

- You will have these symptoms for 3 days.

- There is 1 in 10,000 chance that you will die from this sickness.

If Superior Safety System chicken cost $\$ 0.50$ more per meal than standard chicken, which type of chicken would you purchase?

o Standard

○ Superior Safety System 